\title{
SLC25A13 cDNA cloning analysis using peripheral blood lymphocytes facilitates the identification of a large deletion mutation: Molecular diagnosis of an infant with neonatal intrahepatic cholestasis caused by citrin deficiency
}

\author{
HAN-SHI ZENG ${ }^{1}$, WEI-XIA LIN ${ }^{1}$, SHU-TAO ZHAO ${ }^{1}$, ZHAN-HUI ZHANG ${ }^{2}$, HENG-WEN YANG ${ }^{3}$, \\ FENG-PING CHEN ${ }^{4}$, YUAN-ZONG SONG ${ }^{1}$ and ZHI-NAN YIN ${ }^{3}$ \\ ${ }^{1}$ Department of Pediatrics; ${ }^{2}$ Core Laboratory, The First Affiliated Hospital; ${ }^{3}$ Biomedical Translational Research Institute; \\ ${ }^{4}$ Department of Laboratory Science, The First Affiliated Hospital, Jinan University, Guangzhou, \\ Guangdong 510630, P.R. China
}

Received August 6, 2015; Accepted August 8, 2016

DOI: $10.3892 / \mathrm{mmr} .2016 .5873$

\begin{abstract}
Neonatal intrahepatic cholestasis caused by citrin deficiency (NICCD) is an autosomal recessive disorder resulting from biallelic mutations of the SLC25A13 gene. Due to the lack of well-recognized clinical or biochemical diagnostic criteria, the definitive diagnosis of this disease relies on the genetic analysis of SLC25A13 at present. As novel large deletion/insertion mutations of the $S L C 25 A 13$ gene are difficult to detect using routine DNA analytic approaches, the timely diagnosis of patients with these types of mutations remains a challenge. The present study aimed to examine $S L C 25 A 13$ mutations in an infant with a suspected diagnosis of NICCD. DNA was extracted from blood samples, and $S L C 25 A 13$ mutations were examined by screening for
\end{abstract}

Correspondence to: Professor Yuan-Zong Song, Department of Pediatrics, The First Affiliated Hospital, Jinan University, 613 Huangpu Da Dao Xi, Guangzhou, Guangdong 510630, P.R. China

E-mail: songyuanzong@vip.tom.com

Abbreviations: CD, citrin deficiency; NICCD, neonatal intrahepatic cholestasis caused by citrin deficiency; AGC2, aspartate/glutamate carrier isoform 2; PBLs, peripheral blood lymphocytes; PCR, polymerase chain reaction; LA-PCR, long and accurate-PCR; RT-PCR, reverse transcription-PCR; ALT, alanine transaminase; AST, aspartate transaminase; GGT, $\gamma$-glutamyl transpeptidase; TBA, total bile acid; Tbil, total bilirubin; Dbil, direct bilirubin; Ibil, indirect bilirubin; MCT, medium-chain triglyceride; GC-MS, gas chromatography-mass spectrometry; MS-MS, tandem mass spectrometry; ASVs, alternative splice variants; CMV, cytomegalovirus; NADH, reduced form of nicotinamide-adenine dinucleotide

Key words: SLC25A13, citrin deficiency, peripheral blood lymphocytes, cDNA cloning high-frequency mutations and Sanger sequencing. Reverse transcription-polymerase chain reaction and cDNA cloning analyses were then performed using peripheral blood lymphocytes (PBLs) to identify the obscure mutation. The results demonstrated that the infant was heterozygous for a paternally-inherited mutation, c.851_854del4, and a maternally-inherited large deletion, c.1019_1177+893del, which has not been reported previously. A positive diagnosis of NICCD was made, and the infant responded favorably to a galactose-free and medium-chain triglyceride-enriched formula. The present study confirmed the effectiveness of this formula in NICCD therapy, enriched the SLC $25 \mathrm{~A} 13$ mutational spectrum and supported the feasibility of cDNA cloning analysis using PBLs as a molecular tool for facilitating the identification of large SLC25A13 deletions.

\section{Introduction}

Citrin deficiency (CD) is an autosomal recessive disorder caused by biallelic mutations in the SLC $25 A 13$ gene, which encodes citrin, the aspartate/glutamate carrier isoform 2 (AGC2) (1-3). In 1999, Kobayashi et al (4) cloned the SLC25A13 gene, providing a foundation for subsequent investigations of CD. An increasing number of patients have been diagnosed with CD, not only in Asia (5-16), but also in Europe (17-20) and North America (21-24). Currently, CD has been recognized as a worldwide panethnic disease.

Neonatal intrahepatic cholestasis caused by CD (NICCD) is a $\mathrm{CD}$ phenotype found in neonates and infants, and its diagnosis relies on the genetic analysis of $S L C 25 A 13$ (2). However, conventional DNA analytic approaches, including PCR and Sanger sequencing, cannot identify all SLC25A13 mutations (25). Obscure mutations are usually large insertions/deletions $(12,24,26)$, and the early diagnoses of patients with these types of mutations require time-consuming and expensive experimental techniques, which presents a constant challenge. In the present study, a novel large SLC25A13 deletion was identified in a patient with NICCD using a diverse 
range of tools, including cDNA cloning analysis of the SLC25A13 gene in the peripheral blood lymphocytes (PBLs) of the infant. The present study reports on the molecular and clinical findings.

\section{Materials and methods}

Subjects and ethical statement. A 6-month-old male infant who was referred to Department of Pediatrics (First Affiliated Hospital, Jinan University, Gangzhou, China) on May 20, 2014 and his parents were enrolled as research subjects. The clinical findings were described as a case report. The data were predominantly collected from the Department of Pediatrics and biochemical analysis was performed in the Department of Laboratory Science. However, partial biochemical or imaging results from the Children's Hospital Affiliated to the Capital Institute of Pediatrics (Beijing, China) were provided by the parents upon request. Written informed consent was obtained from parents prior to the investigation, which was approved by the Committee for Medical Ethics of the First Affiliated Hospital, Jinan University (Guangzhou, China).

Detection of high-frequency mutations and Sanger sequencing. As described previously (10-12,16), peripheral blood samples were collected from the subjects, and DNA was extracted according to the instructions of the genomic DNA extraction kit (Simgen, Hangzhou, China). The four high-frequency SLC25A13 mutations c.851_854del4, c.1638_1660dup, c. $615+5 \mathrm{G}>\mathrm{A}$ and IVS16ins $3 \mathrm{~kb}$, were screened using polymerase chain reaction (PCR)/long and accurate (LA)-PCR and PCR-restriction fragment length polymorphism procedures. All 18 exons and their flanking sequences in the SLC25A13 gene were then sequenced to identify the possible mutations. All PCR amplification in the present study was conducted by using a Mastercycler nexus PCR instrument (Eppendorf, Hamburg, Germany) and Sanger sequencing was performed using a 96-capillary ABI 3730xl DNA Analyzer with BigDye Terminator version 3.1 Cycle Sequencing kit (Thermo Fisher Scientific, Waltham, MA, USA), according to the manufacturer's protocol.

Reverse transcription (RT)-PCR and cDNA cloning analysis. The cDNA cloning was performed as in our previous study $(12,27)$. Briefly, PBLs were isolated from the heparinized blood samples of the infant using lymphocyte separation medium (ICN Biomedicals, Santa Ana, CA, USA). RNAiso Plus (Takara Bio, Inc., Otsu, Japan) was then used to extract the total RNA. Following this procedure, RT-nested PCR was performed. The cDNAs were synthesized from $2 \mu \mathrm{g}$ of total RNA in the presence of primer UP-dT (5'-CGGCAGTGGTAT CAACGCAGAGTAC $\left.(\mathrm{T})_{18}-3^{\prime}\right)$ and 200U MMLV reverse transcriptase (Promega, Beijing, China). The first PCR was carried out in a $50 \mu 1$ volume containing $10 \mu \mathrm{l}$ of $5 \mathrm{x}$ PrimeSTAR buffer $\left(\mathrm{Mg}^{2+}\right.$ plus), $0.5 \mu \mathrm{l}$ of PrimeSTAR HS DNA polymerase (2.5 U/ $\mu 1$, Takara Bio, Inc., Dalian, Liaoning, China), $1 \mu 1$ of cDNA, $1 \mu 1$ of each primer RAS2 (5'-AACGCACGCTGCCTG GCCGTATC-3') and RACEA1 (5'-CCACCTTCACAAATT CATGCGCC-3'; 20 $\mu \mathrm{M}), 4 \mu \mathrm{l}$ of dNTP mixture $(10 \mathrm{mM})$ and $32.5 \mu \mathrm{l}$ PCR-grade water. Following initial denaturation at $94^{\circ} \mathrm{C}$ for $3 \mathrm{~min}, 20$ cycles of DNA amplification were performed $\left(98^{\circ} \mathrm{C}\right.$ for $10 \mathrm{sec}, 60^{\circ} \mathrm{C}$ for $15 \mathrm{sec}, 72^{\circ} \mathrm{C}$ for $4 \mathrm{~min}$ ), followed by a terminal extension at $72^{\circ} \mathrm{C}$ for $7 \mathrm{~min}$. Subsequently, $1 \mu \mathrm{l}$ of the first PCR product was subjected to the second PCR for 30 cycles in $50 \mu \mathrm{l}$ mixture including $10 \mu \mathrm{l}$ of $5 \mathrm{x}$ PrimeSTAR buffer $\left(\mathrm{Mg}^{2+}\right.$ plus), $0.5 \mu \mathrm{l}$ of PrimeSTAR HS DNA polymerase (2.5 U/ $\mu \mathrm{L}$, Takara Bio, Inc), $4 \mu \mathrm{l}$ of dNTP mixture $(10 \mathrm{mM})$, $1 \mu \mathrm{l}$ of each primer RAS3 (5'-GCCGCCGGGACTAGAAGT GAGC-3') and Ex18R (5'-TGCTTCATTCCCAGGAGGGA-3'; $20 \mu \mathrm{M}$ ), and $32.5 \mu \mathrm{l}$ PCR-grade water. The PCR thermocycling conditions were: $94^{\circ} \mathrm{C}$ for $3 \mathrm{~min}$ followed by 30 cycles of $98^{\circ} \mathrm{C}$ for $10 \mathrm{sec}, 60^{\circ} \mathrm{C}$ for $5 \mathrm{sec}, 72^{\circ} \mathrm{C}$ for $2.5 \mathrm{~min}$ and a final extension step at $72^{\circ} \mathrm{C}$ for $10 \mathrm{~min}$. The products were then purified by a gel extraction kit (Omega Bio-Tek, Inc., Norcross, GA, USA) and cloned into the $\mathrm{pMD}^{\mathrm{TM}} 18-\mathrm{T}$ Vector (Takara Bio, Inc.), following which they were transformed into DH5 $\alpha$ Escherichia coli competent cells by means of heat shock and cultured for $12-16 \mathrm{~h}$ at $37^{\circ} \mathrm{C}$. Positive clones were subsequently selected and the SLC25A13 transcripts were sequenced. The sequencing results were aligned with the SLC25A13 cDNA sequence, which was available at http://www.ensembl.org/ by using a DNAman software version 7.212 (Lynnon Corporation, QC, Canada).

LA-PCR approach. Based upon the findings of the cDNA cloning and sequencing, the c.851_854del4 mutation was used as a marker for identifying the obscure mutation in the DNA samples. For LA-PCR, three sets of primers (Fig. 1) were designed and the PCR kit was purchased from Takara Bio, Inc. Every $50 \mu \mathrm{l}$ LA-PCR mixture comprised $0.5 \mu \mathrm{l} \mathrm{LA}$ Taq (5 U/ $\mu \mathrm{l}), 5 \mu 110 \mathrm{x}$ LA Buffer $\left(\mathrm{Mg}^{2+}\right.$ plus), $1 \mu \mathrm{l}$ DNA, $6 \mu 1$ dNTP mixture $(2.5 \mathrm{mM})$, and $35.5 \mu \mathrm{l}$ PCR-grade water and the relevant primer pair (Set A, B and C in Fig. 1, respectively, with $1 \mu \mathrm{l}$ of each primer in $20 \mu \mathrm{M}$ ). The temperature profile was set at $94^{\circ} \mathrm{C}$ for $4 \mathrm{~min}$, followed by 35 cycles at $98^{\circ} \mathrm{C}$ for $11 \mathrm{sec}$, $62^{\circ} \mathrm{C}$ for $40 \mathrm{sec}, 68^{\circ} \mathrm{C}$ for $3 \mathrm{~min}$ and a final extension step at $68^{\circ} \mathrm{C}$ for $10 \mathrm{~min}$. The amplified products were then separated using electrophoresis, purified and sequenced, respectively. The electrophoresis was conducted in an $1.5 \%$ agarose gel (Bio-Rad Laboratories, Inc., Hercules, CA, USA), the target products were purified by a gel extraction kit (Omega Bio-Tek, Inc.).

\section{Results}

Case report. A male infant, aged 2.6 months, was admitted to the Children's Hospital Affiliated to the Capital Institute of Pediatrics due to prolonged jaundice for $>2$ months. As the first child of a non-consanguineous couple, the infant was born at the gestational age of 38 weeks with a birth weight of $2.35 \mathrm{~kg}$ [-2.1 standard deviations (SD)] and a body length of $48 \mathrm{~cm}$ (-0.9 SD). The father and grandmother had hypercholesterolemia. There was no family history of any other genetic disease.

Physical examination revealed a body weight of $4.7 \mathrm{~kg}$ (-2.0 SD), body length of $55 \mathrm{~cm}(-2.2 \mathrm{SD})$ and a head circumference of $37.5 \mathrm{~cm}$ (-1.7 SD). Jaundiced skin and sclera were observed. No positive signs were found in the two lungs or the heart. The liver was palpable with a soft edge $3 \mathrm{~cm}$ below the right costal margin. Biochemical analysis showed increased levels of serum $\gamma$-glutamyl transpeptidase, total 
Table I. Biochemical alterations over time in the patient with neonatal intrahepatic cholestasis caused by citrin deficiency.

\begin{tabular}{|c|c|c|c|c|c|c|c|c|c|c|c|}
\hline \multirow{2}{*}{$\begin{array}{l}\text { Biochemical } \\
\text { index }\end{array}$} & \multirow{2}{*}{$\begin{array}{l}\text { Normal } \\
\text { range }\end{array}$} & \multicolumn{9}{|c|}{ Age (months) } & \multirow[b]{2}{*}{18} \\
\hline & & $2.6^{\mathrm{a}}$ & 3.1 & $3.3^{\mathrm{b}}$ & $3.5^{\mathrm{c}}$ & 4 & 4.4 & 7.3 & 9.4 & 12 & \\
\hline ALT (U/l) & $5-40$ & 66.0 & 26.00 & 113.0 & 75.7 & 24.0 & 42.0 & 71.0 & 47.00 & 46.0 & 27 \\
\hline AST (U/1) & $5-40$ & 132.0 & 52.00 & 578.0 & 134.3 & 47.0 & 58.0 & 63.0 & 48.00 & 36.0 & 47 \\
\hline GGT (U/l) & $8-50$ & 171.0 & 152.00 & 215.0 & 165.3 & 139.0 & 58.0 & 22.0 & 25.00 & 21.0 & 21 \\
\hline ALP (U/l) & $20-500$ & 810.0 & 396.00 & 395.0 & - & 412.0 & 285.0 & 241.0 & 198.0 & 208.0 & 240 \\
\hline $\mathrm{TP}(\mathrm{g} / \mathrm{l})$ & $60.0-83.0$ & 45.8 & 52.00 & 48.2 & - & 54.1 & 56.3 & 57.8 & 68.20 & 67.9 & 73.4 \\
\hline Alb (g/l) & $35.0-55.0$ & 32.2 & 35.30 & 38.2 & - & 39.1 & 40.1 & 45.8 & 50.30 & 50.8 & 50.3 \\
\hline Glb (g/l) & $20.0-30.0$ & 13.6 & 16.70 & 10.0 & - & 15.0 & 16.2 & 12.0 & 17.90 & 17.1 & 23.1 \\
\hline Tbil $(\mu \mathrm{mol} / \mathrm{l})$ & 2-19 & 174.7 & 134.90 & 192.8 & 126.2 & 44.9 & 13.3 & 11.4 & 5.90 & 7.0 & 8.0 \\
\hline Dbil $(\mu \mathrm{mol} / \mathrm{l})$ & $0-6$ & 99.7 & 60.40 & 83.0 & 66.7 & 18.5 & 4.5 & 2.0 & 1.30 & 1.5 & 2.2 \\
\hline Ibil $(\mu \mathrm{mol} / \mathrm{l})$ & $2.56-20.9$ & 75.0 & 74.50 & 109.8 & 59.5 & 25.4 & 8.8 & 9.4 & 4.60 & 5.5 & 5.8 \\
\hline $\mathrm{TBA}(\mu \mathrm{mol} / \mathrm{l})$ & 0-10 & 210.2 & 168.83 & 170.9 & 123.2 & 64.5 & 25.6 & 6.9 & 7.36 & 7.3 & 0.5 \\
\hline
\end{tabular}

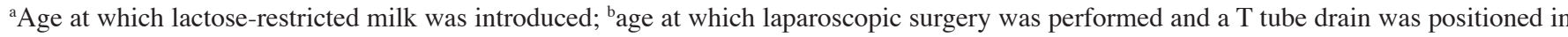
the gallbladder bed; ${ }^{c}$ age at which the T tube was removed and lactose-free/MCT-enriched therapeutic formula was introduced.

Table II. SLC25A13 ASVs detected by cDNA analysis using peripheral blood lymphocytes of the patient with neonatal intrahepatic cholestasis caused by citrin deficiency.

\begin{tabular}{|c|c|c|c|c|c|}
\hline Allele & Name & ASV & Annotation & Clone (n) & Percentage \\
\hline \multirow[t]{5}{*}{ Maternally-inherited } & M-01 & r.213_468del; r.1019_1177del & Exon 4,5 and 11 skipping & 1 & 16.7 \\
\hline & M-02 & r.213_328del; r.1019_1177del & Exon 4 and 11 skipping & 1 & 16.7 \\
\hline & M-03 & $r .1019 \_1177 \mathrm{del}$ & Exon 11 skipping & 2 & 33.3 \\
\hline & M-04 & $\begin{array}{l}r .213 \_328 d e l ; \text { r.1019_1177del; } \\
r .1311 \_1312 \text { ins1311+102_1311+176 }\end{array}$ & Exon 4 and 11 skipping & 1 & 16.7 \\
\hline & M-05 & $\begin{array}{l}\text { r.213_468del; r.755_933del; } \\
\text { r.1019_1177del }\end{array}$ & $\begin{array}{l}\text { Exon } 4,5,8,9 \text { and } 11 \\
\text { skipping }\end{array}$ & 1 & 16.7 \\
\hline Paternally-inherited & F-01 & r.213_328del; r.851_854del4 & Exon 4 skipping & 1 & 100 \\
\hline
\end{tabular}

ASV, alternative splice variant.

bilirubin, direct bilirubin and total bile acids, as shown in Table I, indicating the presence of cholestasis. The levels of cytomegalovirus (CMV) DNA in the urine and breast milk were $5.57 \times 10^{3}$ copies $/ \mathrm{ml}$ and $1.07 \times 10^{4}$ copies $/ \mathrm{ml}$, respectively.

According the above findings, the patient was suspected to have CMV hepatitis, and breastfeeding was terminated followed by the commencement of galactose-restricted milk and ganciclovir treatment. As a result, the urinary CMV DNA levels became negative; however, the infant remained jaundiced and there was no marked improvement in biochemistry (Table I). Laparoscopy and cholangiography were then performed at 3.3 months (in a hospital in Beijing, China), revealing normal bile ducts, however, liver biopsy showed microvesicular steatosis, mildly hepatocellular and canalicular cholestasis, moderate inflammatory cell infiltration in the portal tracts and perisinusoidal fibrosis. Marginally elevated levels of citrulline, ornithine and methionine were found on tandem mass spectrometry (MS-MS) analysis of the serum amino acids; whereas a high level of 4-hydroxyphenyllactate was identified in the urinary gas chromatography (GC)-MS assay (both previously performed at a hospital in Beijing, China).

In view of the above findings, the patient was suspected to have NICCD, and was switched to a galactose-free, MCT-enriched formula at the age of 3.5 months. His jaundice subsided rapidly, and the biochemical abnormalities improved markedly within half a month. At the 12-month follow-up, the patient had a body weight of $10.0 \mathrm{~kg}(-0.1 \mathrm{SD})$, body length of $74 \mathrm{~cm}$ (-1.2 SD) and head circumference of $46 \mathrm{~cm}$ (-0.4 SD), and cholestatic indices were no longer detected on biochemical assessment. The patient (aged, 6 months) was referred to our hospital for SLC25A13 genetic analysis.

Results of DNA sequencing and cDNA cloning analysis. Screening of high-frequency mutations and Sanger sequencing of the $S L C 25 A 13$ gene in the infant revealed a 


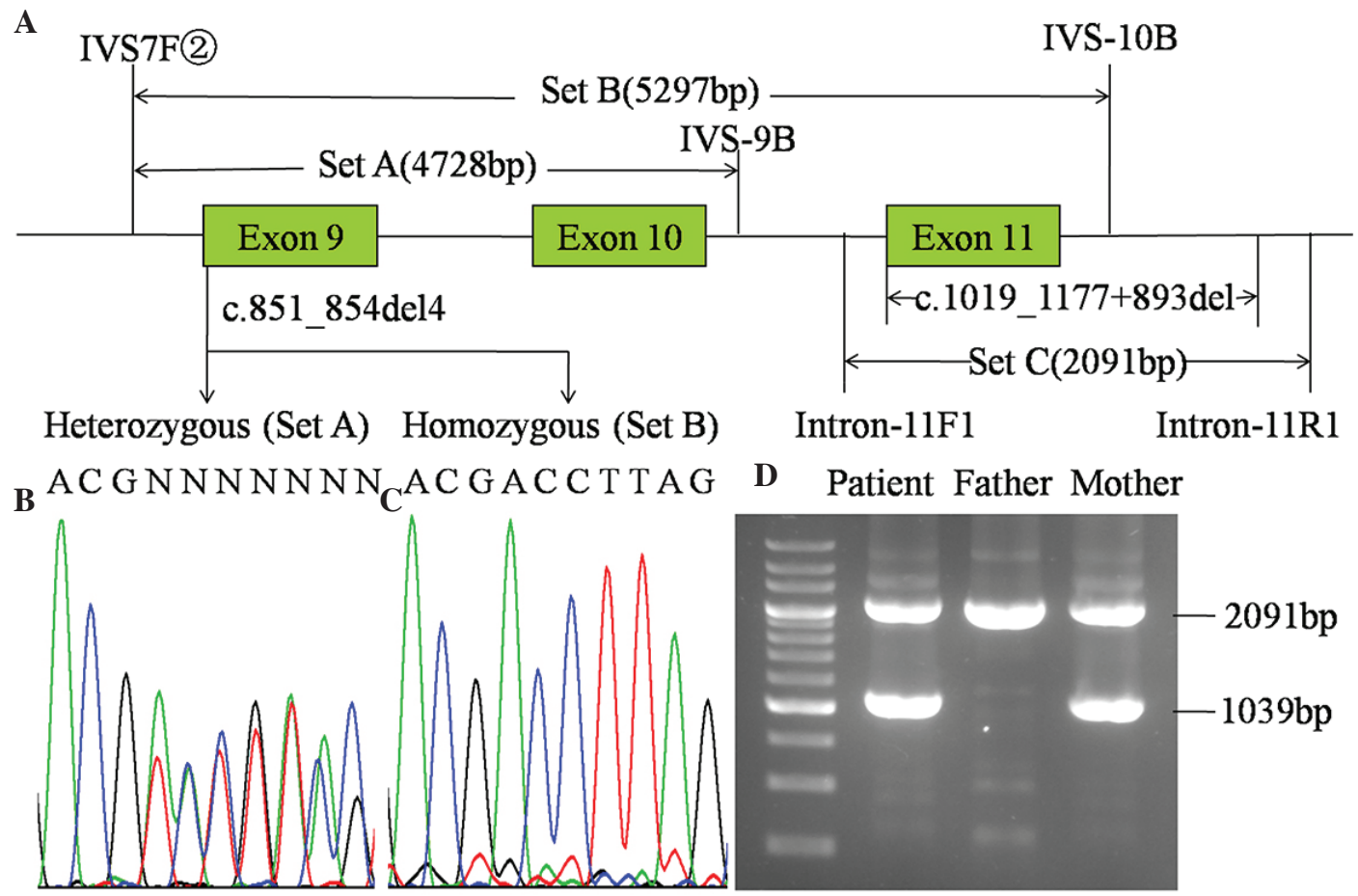

Figure 1. Identification of the large deletion, c.1019_1177+893del. (A) Positions of the primer sets are shown in the upper lane. Primer sequences were Intron11-F1, 5'-TGAGGTTGGGCTGTAGCAATGTG-3'; Intron11-R1, 5'-GAACTGAAACGGCAAGAGTGGAAG-3'; IVS7F(2), 5'-GGTATATTTGTTGCTTGTGTTTG-3'; IVS-9B, 5'-CCTGTCTTTGGAA GGCCTGA-3' and IVS-10B, 5'-CTAGATGCCTCCAGCCTACT-3', respectively. The c.851_854del mutation was (B) heterozygous when amplified using primer set A and homozygous when amplified using (C) primer set B. (D) Long and accurate polymerase chain reaction analysis using primer set $\mathrm{C}$ yielded an unexpected band of $\sim 1 \mathrm{~kb}$ inherited from the mother, in addition to the expected 2,091 bp product from the father.

\begin{abstract}
5'-tgaggttgggctgtagcaatgtgccttaatttaaaatatctatgacatccttttattaggggatacttgaatgaaaaccctcaat tgtttattaaagatataagaaaggtagtactgttttaaaatctgtatttaaaattcaaaacacatttctttctcagtcttgtccttgactt taactaccttcttcttcttctgacctatcttactttcttctgagataatgatattgtttaatttlag CTGTTGG AGCCACTGCT GTGTATCCTATCG ATCTTGTAAAAACTCGAATGCAGAACCAACGATCAACTGGCTC TITTGTGGGAG AACTCATGTATAAAAACAGCTTTGACTGTTTTAAGAAAGTGCTACG CTATGAAGGCTTCTTTGGACTGTATAG AGgttagtgccacatgctcaatacctgttaggtgaaataa cactcaaaggtttggtttctcatcttagtgcctgacatgaattagcaagactgcgttaaaatggaaatacagcagatttt caattatccatgctaatgggagtagg ttggagg catctagggcttggctaatcaaaacagcccataatctgaaaatt atttatagtgctctg ttg tatgttttatttcttaaaataataaattatttttataagcatcttccgtgaatttttgaaaggctcac attgtttgcatccttgaagtactctattctccagctaacagggaaaggtattctgccaccaggacaaagcctactcag gattcatgattttcctggaatacaccacaaaaaagataacgaagggttcagtagagctctctttgctgcttcatcctg aattaaagttgcccctttcttcatctgactctcaacccaatggag ttgattcacacacccctctagccaaggtttcccc ccactgagacagcctgaaacaggtaatccttctttctccacctttcctttaaccatctaaggttcattaag caatggaa gtagtagcagagagtatgtcatcactgatggaaaggatcccacagaccctgactgctttccactgg attggecg aaggagacttctcaactgttcttcggggattgccttctacgagaaggaaacagtgtttctgcatcagttaaaatacag tatcacaaggcagttcaaactcagctgctttataatttggcagcggcaaagctggcagagttttcctcctctcccct actaatgctctctctagatgaagaaaacagtatttagtactctgctgaggtggacggtgaaactggcagacatggaaa cctgtgcctctggg cctcttctgccatctgctgactctagtcttcaaattaattaccccagttaaaaaaaacaaaaaggataaac ctttcttgaaacctctcaccttagaagccagaaagtctcaaactccagagaagttccatttgcaggtcctattgtgtaggtaggt agcccccatcaaaggccttttgatctttgctctgccctctttccttatcccctgcctcttcttacaatttggaaggtctttgacctcagg tgattgatgatgaccctttcagggtcactgccttccatttgaaatgctttcttccctgatggcaacaactttgcaaatgaaatggctt ccaagtagtacaagg ttaatgtcacagttcctattctgcagtgagtcagg caaaattggccgccttacctgtccatatgggtggtt tttggaagggaaatctogagtctcaagtctgggcagacatctgagcattgcttcataaactacttttgggctttcttggtattagat taaatgtcaaggatgcctttagaattgtaagaatgcttcccaacactgctcagtgtctttaatttgcttaagttgatttttattttgagtc ctttttctcgatctttgaccatacctggcaggtctgattttgg ttacgtctatatttccctttgcaacctgtactgttggcaactagaa gtgtgcctgagtactgagtgctgagctaatgtggg ctatgcaaagagg cttccactcttgcogtttca-3'
\end{abstract}

Figure 2. Illustration of the nucleotide sequences of the LA-PCR products. The large deletion, c.1019_1177+893del (represented in bold brown, 1,052 bp in size) involved the entire exon 11 (upper case letters) and partial sequences of intron 11 (lower case letters). Underlined regions represent the positions of the Intron11-F1 and Intron11-R1 primers for LA-PCR, which yielded the expected band of 2,091 bp, and an unexpected band of 1,039 bp resulting from the large deletion. The lower-case letters in green represent the undeleted sequences in introns 10 and 11, respectively. LA-PCR, long and accurate polymerase chain reaction. 
paternally-inherited mutation, c.851_854del4. Following SLC25A13 cDNA cloning analysis using PBLs, five alternative splice variants (ASVs) were identified from the maternally-inherited SLC25A13 allele, with the common feature of exon 11 skipping (r.1019_1177del), as shown in Table II. This suggested the existence of a large insertion or deletion within the DNA fragment spanning the region between intron 10 and intron 11 in the SLC25A13 gene.

Identification of the large deletion. The targeted DNA span between intron 10 and intron 11, described above, was then investigated to identify the obscure mutation of maternal origin. As shown in Fig. 1, the c.851_854del4 mutation was heterozygous in the PCR product using primer set A, and was homozygous with primer set $\mathrm{B}$. These results led to the design of primer set $\mathrm{C}$, with which the LA-PCR amplification procedure yielded an unexpected product of $\sim 1.0 \mathrm{~kb}$ in the infant and the mother in addition to the expected 2,091 bp band in all family members. As shown in Fig. 2, direct sequencing of the unexpected product revealed a large deletion, c.1019_1177+893del, with a length of 1,052 bp, entirely involving exon 11 and partially involving intron 11.

\section{Discussion}

The intro- and extra-uterine growth retardation, prolonged jaundice, liver enlargement and biochemical alterations, which were exhibited by the infant in the present study were all non-pathognomonic. However, the metabolome and hepatopathologic findings were consistent with the relevant results in cases of NICCD reported previously $(10,28)$, warranting the genetic analysis of SLC25A13 in the present study. Based on the findings of cDNA cloning analysis using PBLs and the subsequent LA-PCR analysis and Sanger sequencing procedures, the maternally-inherited novel deletion, c.1019_1177+893del, was identified in the patient. To the best of our knowledge, this mutation has not been reported previously. The identification of this large deletion, in addition to the paternally-inherited c.851_854del4 mutation identified, constituted reliable evidence for a definitive diagnosis of NICCD in the infant.

The novel large deletion caused the production of the r.1019_1177del (exon 11 skipping) ASV, which predictively led to the loss of 53 amino acid residues (codons 340-392) in the citrin protein. According to the functional domains of citrin (4), the loss of these residues produces a truncated citrin molecule without the first and second transmembrane domains. Consequently, the AGC2 function was impaired in all hepatocytes, resulting in the laboratory and clinical manifestations observed in the infant with NICCD. Of note, this pathogenic process, resulting from the novel large deletion, is consistent with that underlying the IVS11+1G>A mutation reported previously, which also resulted in exon 11 skipping (r. 1019_1177del) during the splicing of pre-mRNA (4).

Accumulating clinical evidence has suggested the therapeutic effectiveness of galactose-free and MCT-enriched formulas in patients with $\operatorname{NICCD}(9,16,29,30)$, and the clinical findings in the present study further supported this. A key biochemical alteration of citrin deficiency is the increased cytosolic $\mathrm{NADH} / \mathrm{NAD}^{+}$ratio in hepatocytes, and a malate-citrate shuttle may be a form of compensation for the increased ratio (1). The pathophysiology of CD may be associated with an energy shortage in the liver caused by impairment of glycolysis caused by the increased $\mathrm{NADH} / \mathrm{NAD}^{+}$ratio $(29,31)$. The metabolism of galactose in hepatocytes further increases this ratio and reduces the production of mitochondrial acetyl-CoA, a component of the malate-citrate shuttle. By contrast, MCT supplementation can produce an excess of acetyl-CoA in the mitochondria of hepatocytes, providing energy and improving the cytosolic $\mathrm{NADH} \mathrm{NAD}^{+}$ratio via the malate-citrate shuttle $(29,31)$. These mechanisms explain the clinical and laboratory improvements of the patient examined in the present study shortly following the introduction of the galactose-free and MCT-enriched formula.

In conclusion, the present study reported on clinical and molecular investigations of an infant with NICCD, who was confirmed to be a compound heterozygote of the c.851_854del4 mutation and a novel large deletion c.1019_1177+893del in the SLC25A13 gene. These findings confirmed the effectiveness of the galactose-free and MCT-enriched formula on NICCD therapy, enriched the SLC25A13 mutational spectrum, and supported the feasibility of $S L C 25 A 13$ cDNA cloning analysis using PBLs as a molecular tool to facilitate the identification of large SLC25A13 deletion.

\section{Acknowledgements}

The present study was financially supported by the Cultivation Foundation for Scientific Research (grant no. 2014208) approved by the First Affiliated Hospital, Jinan University, the Medical Scientific Research Foundation of Guangdong Province (grant no. A2014385), the Fundamental Research Funds for the Central Universities (grant no. 21615470), and the National Natural Science Foundation of China (grant no. 81270957). The authors would like to thank Mrs Charron Cote (Biomedical Translational Research Institute, Jinan University, Guangzhou, China) for her grammatical contributions.

\section{References}

1. Saheki T and Kobayashi K: Mitochondrial aspartate glutamate carrier (citrin) deficiency as the cause of adult-onset type II citrullinemia (CTLN2) and idiopathic neonatal hepatitis (NICCD). J Hum Genet 47: 333-341, 2002.

2. Kobayashi K, Saheki T and Song YZ: Citrin Deficiency. In: Pagon RA, Adam MP, Ardinger HH, Bird TD, Dolan CR, Fong CT, Smith RJH, Stephens K, editors. GeneReviews ${ }^{\circledR}$ [Internet]. Seattle (WA): University of Washington, Seattle; 1993-2014, 2005 Sep 16 [updated 2014 Jul 31].

3. Palmieri F: Mitochondrial transporters of the SLC25 family and associated diseases: A review. J Inherit Metab Dis 37: 565-575, 2014.

4. Kobayashi K, Sinasac DS, Iijima M, Boright AP, Begum L, Lee JR, Yasuda T, Ikeda S, Hirano R, Terazono H, et al: The gene mutated in adult-onset type II citrullinaemia encodes a putative mitochondrial carrier protein. Nat Genet 22: 159-163, 1999.

5. Bijarnia-Mahay S, Häberle J, Rüfenacht V, Shigematsu Y, Saxena R and Verma IC: Citrin deficiency: A treatable cause of acute psychosis in adults. Neurol India 63: 220-222, 2015.

6. Ko JM, Kim GH, Kim JH, Kim JY, Choi JH, Ushikai M, Saheki T, Kobayashi K and Yoo HW: Six cases of citrin deficiency in Korea. Int J Mol Med 20: 809-815, 2007. 
7. Lee BH, Jin HY, Kim GH, Choi JH and Yoo HW: Nonalcoholic fatty liver disease in 2 siblings with adult-onset type ii citrullinemia. J Pediatr Gastroenterol Nutr 50: 682-685, 2010.

8. Ngu HL, Zabedah MY and Kobayashi K: Neonatal intrahepatic cholestasis caused by citrin deficiency (NICCD) in three Malay children. Malays J Pathol 32: 53-57, 2010.

9. Ohura T, Kobayashi K, Tazawa Y, Abukawa D, Sakamoto O, Tsuchiya S and Saheki T: Clinical pictures of 75 patients with neonatal intrahepatic cholestasis caused by citrin deficiency (NICCD). J Inherit Metab Dis 30: 139-144, 2007.

10. Song YZ, Li BX, Chen FP, Liu SR, Sheng JS, Ushikai M, Zhang $\mathrm{CH}$, Zhang T, Wang ZN, Kobayashi K, et al: Neonatal intrahepatic cholestasis caused by citrin deficiency: Clinical and laboratory investigation of 13 subjects in mainland of China. Dig Liver Dis 41: 683-689, 2009.

11. Song YZ, Deng M, Chen FP, Wen F, Guo L, Cao SL, Gong J, $\mathrm{Xu} \mathrm{H}$, Jiang GY, Zhong L, et al: Genotypic and phenotypic features of citrin deficiency: Five-year experience in a Chinese pediatric center. Int J Mol Med 28: 33-40, 2011.

12. Song YZ, Zhang ZH, Lin WX, Zhao XJ, Deng M, Ma YL, Guo L, Chen FP, Long XL, He XL, et al: SLC25A13 gene analysis in citrin deficiency: Sixteen novel mutations in East Asian patients, and the mutation distribution in a large pediatric cohort in China. PLoS One 8: e74544, 2013.

13. Thong MK, Boey CC, Sheng JS, Ushikai M and Kobayashi K: Neonatal intrahepatic cholestasis caused by citrin deficiency in two Malaysian siblings: Outcome at one year of life. Singapore Med J 51: e12-e14, 2010.

14. Treepongkaruna S, Jitraruch S, Kodcharin P, Charoenpipop D Suwannarat P, Pienvichit P, Kobayashi K and Wattanasirichaigoon D: Neonatal intrahepatic cholestasis caused by citrin deficiency: Prevalence and SLC25A13 mutations among Thai infants. BMC Gastroenterol 12: 141, 2012.

15. Yeh JN, Jeng YM, Chen HL, Ni YH, Hwu WL and Chang MH: Hepatic steatosis and neonatal intrahepatic cholestasis caused by citrin deficiency (NICCD) in Taiwanese infants. J Pediatr 148: 642-646, 2006

16. Zeng HS, Zhao ST, Deng M, Zhang ZH, Cai XR, Chen FP and Song YZ: Inspissated bile syndrome in an infant with citrin deficiency and congenital anomalies of the biliary tract and esophagus: Identification and pathogenicity analysis of a nove SLC25A13 mutation with incomplete penetrance. Int J Mol Med 34: 1241-1248, 2014.

17. Avdseva-Tzavella DM, Ivanova MB, Todorov TP, Todorova AP, Panteleeva EI, Tincheva SS, Lazarova EA, Kathom HM, Yaneva PG and Tincheva RS: First Bulgarian case of citrin deficiency caused by one novel and one recurrent mutation in the SLC25A13 gene. Genet Couns 25: 271-276, 2014.

18. Fiermonte G, Parisi G, Martinelli D, De Leonardis F, Torre G, Pierri CL, Saccari A, Lasorsa FM, Vozza A, Palmieri F and Dionisi-Vici C: A new Caucasian case of neonatal intrahepatic cholestasis caused by citrin deficiency (NICCD): A clinical, molecular, and functional study. Mol Genet Metab 104: 501-506, 2011.
19. Hutchin T, Preece MA, Hendriksz C, Chakrapani A, McClelland V, Okumura F, Song YZ, Iijima M, Kobayashi K, Saheki T, et al: Neonatal intrahepatic cholestasis caused by citrin deficiency (NICCD) as a cause of liver disease in infants in the UK. J Inherit Metab Dis 32 (Suppl 1): S151-S155, 2009.

20. Vitoria I, Dalmau J, Ribes C, Rausell D, García AM, López-Montiel J and Rubio V: Citrin deficiency in a Romanian child living in Spain highlights the worldwide distribution of this defect and illustrates the value of nutritional therapy. Mol Genet Metab 110: 181-183, 2013.

21. Dimmock D, Kobayashi K, Iijima M, Tabata A, Wong LJ, Saheki T, Lee B and Scaglia F: Citrin deficiency: A novel cause of failure to thrive that responds to a high-protein, low-carbohydrate diet. Pediatrics 119: e773-e777, 2007.

22. Dimmock D, Maranda B, Dionisi-Vici C, Wang J, Kleppe S, Fiermonte G, Bai R, Hainline B, Hamosh A, O'Brien WE, et al: Citrin deficiency, a perplexing global disorder. Mol Genet Metab 96: 44-49, 2009.

23. Ricciuto A and Buhas D: A novel citrin deficiency mutation in a cholestatic infant. J Pediatr Gastroenterol Nutr 59: e52, 2014.

24. Wong LJ, Dimmock D, Geraghty MT, Quan R, Lichter-Konecki U, Wang J, Brundage EK, Scaglia F and Chinault AC: Utility of oligonucleotide array-based comparative genomic hybridization for detection of target gene deletions. Clin Chem 54: 1141-1148, 2008.

25. Tokuhara D, Iijima M, Tamamori A, Ohura T, Takaya J, Maisawa S, Kobayashi K, Saheki T and Yamano T: Novel diagnostic approach to citrin deficiency: Analysis of citrin protein in lymphocytes. Mol Genet Metab 90: 30-36, 2007.

26. Tabata A, Sheng JS, Ushikai M, Song YZ, Gao HZ, Lu YB, Okumura F, Iijima M, Mutoh K, Kishida S, et al: Identification of 13 novel mutations including a retrotransposal insertion in SLC25A13 gene and frequency of 30 mutations found in patients with citrin deficiency. J Hum Genet 53: 534-545, 2008.

27. Zhang ZH, Lin WX, Deng M, Zhao XJ and Song YZ: Molecular analysis of SLC25A13 gene in human peripheral blood lymphocytes: Marked transcript diversity, and the feasibility of cDNA cloning as a diagnostic tool for citrin deficiency. Gene 511: 227-234, 2012.

28. Kimura A, Kage M, Nagata I, Mushiake S, Ohura T, Tazawa Y, Maisawa S, Tomomasa T, Abukawa D, Okano Y, et al: Histological findings in the livers of patients with neonatal intrahepatic cholestasis caused by citrin deficiency. Hepatol Res 40: 295-303, 2010.

29. Hayasaka K, Numakura C, Toyota K and Kimura T: Treatment with lactose (galactose)-restricted and medium-chain triglyceride-supplemented formula for neonatal intrahepatic cholestasis caused by citrin deficiency. JIMD Rep 2: 37-44, 2012.

30. Zhang ZH, Lin WX, Deng M, Zhao ST, Zeng HS, Chen FP and Song YZ: Clinical, molecular and functional investigation on an infant with neonatal intrahepatic cholestasis caused by citrin deficiency (NICCD). PLoS One 9: e89267, 2014.

31. Hayasaka K, Numakura $C$ and Watanabe $H$ : Treatment and pathomechanism of citrin deficiency. Brain Nerve 67: 739-747, 2015 (In Japanese). 